
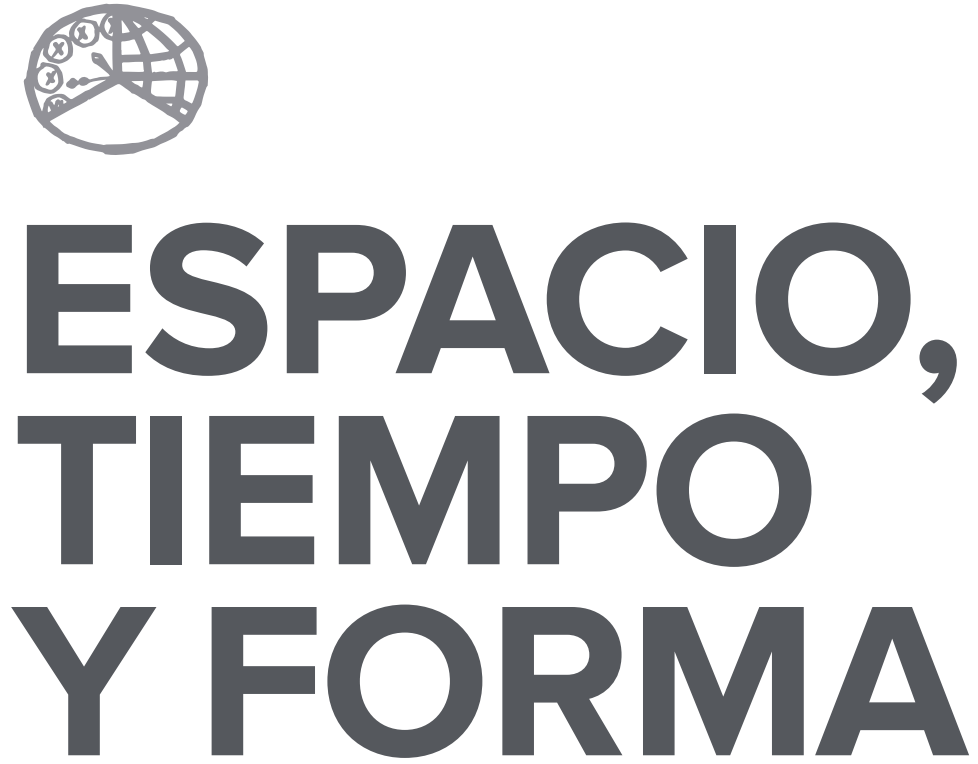

AÑO 2017

ISSN 0214-9745

E-ISSN 2340-1362

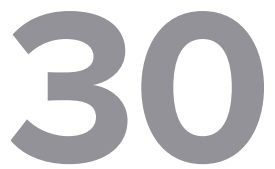

SERIE III HISTORIA MEDIEVAL

REVISTA DE LA FACULTAD DE GEOGRAFÍA E HISTORIA 


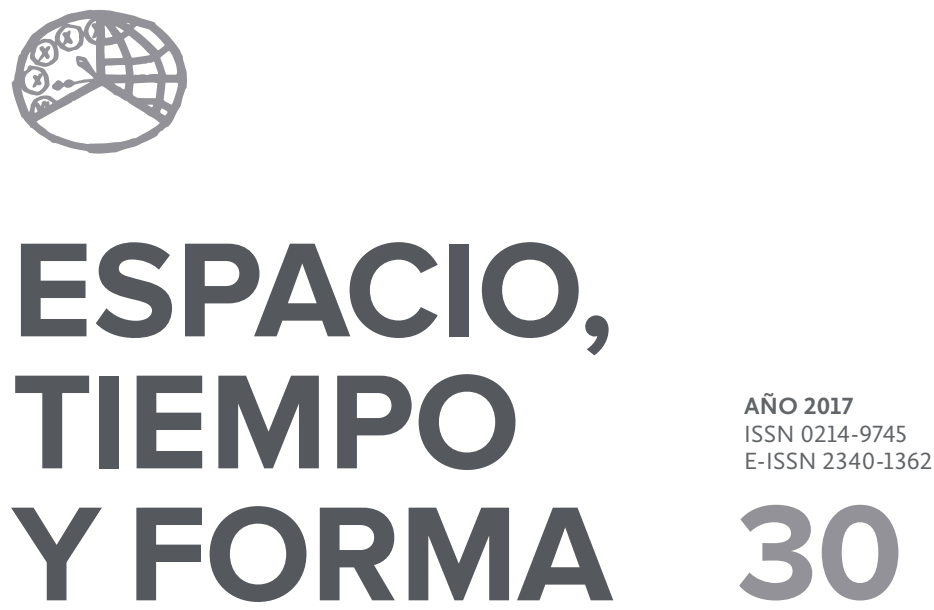

SERIE III HISTORIA MEDIEVAL

REVISTA DE LA FACULTAD DE GEOGRAFÍA E HISTORIA

http://dx.doi.org/10.5944/etfiii.30.2017

\section{UกED}

UNIVERSIDAD NACIONAL DE EDUCACIÓN A DISTANCIA 
La revista Espacio, Tiempo y Forma (siglas recomendadas: ETF),

de la Facultad de Geografía e Historia de la UNED, que inició su publicación el año 1988, está organizada de la siguiente forma:

$$
\begin{aligned}
& \text { SERIE I - Prehistoria y Arqueología } \\
& \text { SERIE II - Historia Antigua } \\
& \text { SERIE III - Historia Medieval } \\
& \text { SERIE IV - Historia Moderna } \\
& \text { SERIE V - Historia Contemporánea } \\
& \text { SERIE VI - Geografía } \\
& \text { SERIE VII - Historia del Arte }
\end{aligned}
$$

Excepcionalmente, algunos volúmenes del año 1988 atienden a la siguiente numeración:
N. ${ }^{\circ} 1 \quad-$ Historia Contemporánea
N. ${ }^{\circ} 2-$ Historia del Arte
N. ${ }^{\circ} 3-$ Geografía
N. ${ }^{\circ} 4 \quad-$ Historia Moderna

ETF no se solidariza necesariamente con las opiniones expresadas por los autores.

UNIVERSIDAD NACIONAL DE EDUCACIÓN A DISTANCIA

Madrid, 2017

SERIE III - HISTORIA MEDIEVAL N. ${ }^{\circ} 30,2017$

ISSN 0214-9745 $\cdot$ E-ISSN 2340-1362

DEPÓSITO LEGAL M-21037-1988

URL: ETF III - HISTORIA MEDIEVAL · http://revistas.uned.es/indeX.php/ETFIII

DISEÑO Y COMPOSICIÓN

Carmen Chincoa Gallardo · http://www.laurisilva.net/cch

Impreso en España $\cdot$ Printed in Spain 


\section{ARTÍCULOS}





\title{
LA RUTA ATLANTICA (SIGLOS XIII-XIV): ANÁLISIS DE LA FORMACIÓN DE UNA RUTA COMERCIAL
}

\section{THE ATLANTIC ROUTE (THIRTEENTH AND FOURTEENTH CENTURIES): ANALYSIS OF THE DEVELOPMENT OF A TRADE ROUTE}

Ángel Rozas Español ${ }^{1}$

Recepción: 2016/5/9 . Comunicación de observaciones de evaluadores: 2016/9/13 . Aceptación: 2017/1/10

DOI: http://dx.doi.org/10.5944/etfiii.30.2017.16529

\section{Resumen}

El artículo trata sobre la apertura del estrecho de Gibraltar y el establecimiento de una nueva vía de comercio entre el Mediterráneo y el Canal de la Mancha. Es una revisión historiográfica sobre el comercio marítimo en las costas occidentales de Europa entre los siglos XIII y XIV a través de un análisis articulado en torno a medios de transporte, mercados y mercancías. Además, estudia el papel de los operadores en el desarrollo de esta ruta comercial y el impacto de la misma sobre el declive de las Ferias de Champaña y las navegaciones oceánicas.

\section{Palabras clave}

Ruta atlántica; Estrecho de Gibraltar; comercio marítimo; Ferias de Champaña; navegación oceánica.

\begin{abstract}
The article discusses the opening of the Straights of Gibraltar and the establishment of a new trade route between the Mediterranean and the English Channel. This article re-examines the scholarship on the maritime trade along the Western European coastlines in the thirteenth and fourteenth centuries based on an analysis of the means of transportation, markets and goods. Furthermore, this
\end{abstract}

1. Este trabajo cuenta con la ayuda económica de una beca FPU (Ministerio de Educación - Castilla-La Mancha) y se inscribe dentro del proyecto de investigación HAR2013-44014-P (Ministerio de Economía Industria y Competitividad), titulado: Jerarquías urbanas: Ciudades y villas en Castilla (1400- 1561). C.e.: arozesp@gmail.com 
study examines the role of merchants in the development of the trade route and its effects on the decline of the Champagne fairs and oceanic navigation.

\section{Keywords}

Atlantic Route; Straights of Gibraltar; Seaborne Trade; Champagne Fairs; Oceanic Navigation.

\section{INTRODUCCIÓN}

Desde el último cuarto del siglo XIII, barcos mediterráneos empezaron a comerciar en las costas del Canal de la Mancha, realizando un largo trayecto que debía atravesar el Estrecho de Gibraltar. La continuidad de los intercambios entre estos dos espacios dio lugar a una ruta comercial estable: «la ruta atlántica». El presente artículo es una revisión historiográfica relativa a las relaciones entre el Mediterráneo y el Atlántico en los siglos XIII y XIV, analizando el proceso de formación y desarrollo de dicha ruta y sus consecuencias.

La importancia de este eje marítimo estriba en que supone una alternativa a las rutas continentales que, a través de las Ferias de Champaña, enlazaban el norte de Italia con Flandes. Estos espacios representaban los dos conjuntos económicos más dinámicos de Europa y estaban vinculados gracias a un comercio especializado en productos de la industria textil. Debido a la importancia de estas relaciones norte-sur en el continente europeo, la aparición de una nueva vía plantea a la historiografía tanto el porqué de la misma, como el impacto que produjo.

El análisis que se plantea para alcanzar las respuestas incide en un primer momento en las posibilidades comerciales que existían en el entorno, que son: los medios, los mercados y las mercancías; y, seguidamente la actividad de los comerciantes para consolidar esta vía. Por otro lado, para conocer las posibles consecuencias, se recurre a la comparativa entre los medios terrestres y los marítimos, en concreto la relación entre la aparición de la ruta atlántica y el declive de las Ferias de Champaña, y la navegación oceánica en el siglo XV. 


\section{EL INICIO DE LA RUTA ATLÁNTICA 1277- 1290}

El primer registro de naves mediterráneas en las costas de Flandes y de Inglaterra se remonta al año $1277^{2}$, es decir, alrededor de un siglo después del establecimiento de las Ferias de Champaña3. Roberto López, el primer investigador que trabajó sobre el inicio de esta ruta, señaló que este «retraso» respondía a un problema de costes y mercados ${ }^{4}$. Según sus apreciaciones, los primeros comerciantes en realizar el trayecto, los genoveses, habían llegado ya en el siglo XII hasta las costas francesas del Atlántico, pero no sería hasta finales del siglo XIII cuando se cumplieron tres requisitos que hicieran rentable el viaje: un aumento de la capacidad de carga de las embarcaciones, el desarrollo comercial del sur de la Península Ibérica y la comercialización del alumbre de las minas de Focea. Este último aspecto es de los más relevantes puesto que sería el estímulo que sirvió de detonante para emprender estos viajes y determinaría la preponderancia de operadores genoveses en la nueva ruta.

La publicación de Roberto López es una interesante primera página sobre esta ruta, pero no continúa con su posterior desarrollo. Para comprender las características de la ruta atlántica falta precisar sobre los tres mencionados factores y sobre los operadores, siguiendo su curso con el paso del tiempo. Falta también analizar más en profundidad la interacción de la política y el comercio, hacer una valoración de los medios terrestres y marítimos, así como encajar la nueva ruta en el proceso de expansión comercial europea.

Comenzando como se hace en el mencionado artículo, es necesario señalar que la salida de comerciantes mediterráneos al Atlántico no era una novedad. Si bien, la posibilidad de navegar por esas aguas dependía de la capacidad de atravesar el Estrecho de Gibraltar. Este punto estratégico explica diversos factores que intervienen en la ruta puesto que aquí penetran las aguas del Atlántico hacia el Mediterráneo a unas velocidades de entre cuatro y seis nudos, dificultando la salida hacia el océano, pero no la entrada hacia el Mediterráneo. De esta forma fueron posibles largos viajes de cruzados desde el norte hasta Tierra Santa siglos antes del comienzo de la ruta, aunque no su regreso. Para atravesar el estrecho desde el Mediterráneo eran necesarios puertos de apoyo para esperar vientos favorables y, sobre todo, para conocer la existencia de una posible flota enemiga al otro lado5. Por lo tanto, la presencia de naves mediterráneas en el Atlántico estaba

2. DoemAerd, René: «Les galères génoises dans la Manche et la Mer du Nord à fin du XIII et au début du XIV siècles» Bulletin de L'Institut Historique Belge de Rome, $n^{\circ}$ 19, (1938), pp. 5-76. p. 10.

3. BAUTIER, Robert Henri: «Les foires de Champagne. Recherches sur une évolution historique». Recueils de la Société Jean Bodin, $\mathrm{n}^{\circ}$ 5, (1953), pp. 97-147. pp. 110-111.

4. Sabatino Lopez, Roberto: «Majorcans and Genoese on the North Sea Route in the Thirteenth Century», Revue belge de philologie et d'histoire, $n^{\circ} 29$, (4), (1951), pp. 1163-1179. p. 1164.

5. ArChibalD, Lewis: «Northern sea power and Gibraltar» en ARCHIBALD, Lewis: The sea and medieval powers. Collected studies. London, Variorum Reprints, 1978. p. 110. 
sujeta a un juego de diplomacia entre las potencias de origen de los comerciantes y aquélla que controlase el estrecho. Particularmente, fueron los genoveses quienes mostraron una mayor versatilidad a la hora de pactar con los diferentes poderes que se establecieron a sus orillas ${ }^{6}$. Tal era que, a la altura de I277, durante la «Guerra del Estrecho» entre el reino de Castilla y el sultanato Benimerín, pudieron hacerse paso $^{7}$.

De regreso al hecho de que la navegación entre el Mediterráneo y el Atlántico era posible, esta situación permitió el contacto entre la tradición naval nórdica de origen escandinava y la mediterránea ${ }^{8}$, favoreciendo un aumento de la capacidad de carga y un cambio en la fisonomía de las embarcaciones que abriría la posibilidad a que la nueva ruta comercial fuese rentable. Si bien, este proceso es controvertido en cuanto a su rapidez y sus orígenes ${ }^{9}$, en lo relativo a la ruta la cuestión gira en torno al tipo de embarcación utilizado: la coca mediterránea, una adaptación del kogge escandinavo, o una adaptación de la galera. Resulta difícil discernir cuál de los dos barcos había logrado un mayor tonelaje a finales del siglo $\mathrm{XIII}^{\mathrm{I}}$. Lo cierto es que ambos transitaron la ruta atlántica en sus comienzos: el

6. ConstABLE, Olivia Remi: At the edge of the west: International trade and traders in Muslim Spain (1000-1250). Ann Arbor, University Microfilms International, 1989. pp. 102-115. Un ejemplo de este dinamismo es en el siglo XII cuando apoyan a Alfonso VII para conquistar Almería en 1147 y en 1153 pactan con los almohades, quienes reconquistan la propia Almería en 1157. Tras la salida de los almohades en 1228 realizan un tratado con el emir de Sevilla en 1231 el cual se rehace en 1248 con Fernando III, quien ha conquistado Sevilla.

7. Miguel Ángel Ladero Quesada señala en su artículo la importancia del dominio del Estrecho a lo largo de esta guerra que, sin embargo, no afectaría en estos momentos a la apertura de la ruta atlántica al mantenerse Génova al margen del conflicto. LADERO QUESADA, Miguel Ángel: «La Guerra del Estrecho» en Guerra y diplomacia en la Europa Occidental, 1280-1480. XXXI Semana de Estudios Medievales, Estella, 19 a 23 de julio 2004, LADERO QUESADA, Miguel Ángel (et. alii), Pamplona, Institución Príncipe de Viana, 2005, pp. 255-294. p. 267-268. En un sentido similar se pronuncia Antonio Ortega Villoslada, quien señala los pactos de Génova como la garantía del paso del Estrecho. Sin embargo, los años de 1331-1336 fueron los que presentaron mayor inestabilidad, como también indica Lewis Archibald. ORTEGA VILLOSLADA, Antonio: El reino de Mallorca y el mundo atlántico (1230-1349). Evolución político mercantil. Oleiros, Netbiblo, 2008. pp. 48 y 177; ARCHIBALD, Lewis: op. cit. p. 160.

8. El puerto de Sevilla sería un referente en el encuentro de estas dos tradiciones construyéndose barcos de las dos tradiciones. Ferreira Priege, Elisa: «Castilla: La génesis de una potencia marítima de Occidente», en Itinerarios Medievales e identidad hispánica. XXVII Semana de Estudios Medievales. Estella, 17-21 Julio 200, FerreIRA Priege, Elisa (et alii), Pamplona, Fondo de publicaciones del Gobierno de Navarra, 2001. pp. 23-46. p. 35. Otros ejemplos de encuentros entre ambas tradiciones sería el encargo del obispo de Santiago a maestros genoveses para construir barcos en el año 1120 SABATINO LÓPEZ, Roberto: «Majorcans and Genoese... op. cit. p.1164. O también en el siglo XII otro encargo a los genoveses en Bayona, esta vez el monarca inglés solicitando la construcción de galeras. ORTEGA VILLOSLADA, Antonio: «Viaje a Flandes e Inglaterra ¿Cabotaje o recta vía?», Espacio, Tiempo y Forma, Serie III, Ha Medieval, n 16, (2003), pp. 229-250. p. 238. Además de los genoveses, los mallorquines tuvieron también contacto con los barcos del atlántico. AbULAFIA, David: Un emporio mediterráneo: el reino catalán de Mallorca. Barcelona, Omega, 1996. p. 237.

9. Frederic Chaplin Lane en los años 30 del siglo XX y más recientemente Michel Balard defienden que se trató de una «revolución náutica». LANE, Frederic Chapin: Venetian ships and shipsbuilder of the Renaissance. Baltimore, JHUP, 1934; BALARD, Michel: La Méditerranée médiévale: Espaces, itinéraires, comptoirs. Paris, Picard, 2006. Por otra parte, autores como Norbert Ohler sostienen que no hubo cambios sustanciales respecto a la Antigüedad, por lo que los medios de transporte serían un elemento de longue durée. OHLER, Norbert: «l mezzi di trasporto terrestre e marittimi» en GENSINI, Sergio (dir.): Viaggiare nel Medioevo. Roma, Pacini: Fondazione Centro di Studi sulla Civiltà del Tardo Medioevo San Miniato, 2000. Otro autor que trabaja sobre el tema es Marco Tangheroni quien, además de cuestionar el término de «revolución náutica» por la larga duración de los cambios, resalta las influencias bizantinas e islámicas como motivo de las transformaciones en la industria naval medieval. TANGHERONI, Marco: Commercio $e$ navigazione nel medioevo. Roma, Laterza, 1996.

10. Roberto López defiende que, según los registros de los puertos ingleses, las galeras tenían un mayor tonelaje que los kogge. SABATINO LóPEZ, Roberto: «Majorcans and Genoese... op. cit. p. 1166. Sin embargo, Michel Balard aunque 
primer registro, el de I277, muestra que el transporte de mercancías se hizo en galeras $^{\mathrm{II}}$, pero otros viajes de los que se tiene noticia, en $\mathrm{I} 286$ y en $1292^{12}$, fueron emprendidos por cocas.

Sin embargo, es posible determinar qué embarcación era más apropiada al tener en cuenta que se trataba de un viaje hacia aguas poco conocidas. De este modo, que el primer viaje lo realizasen galeras y no cocas, no es sólo significativo, sino que probablemente responda a la necesidad de asegurar el éxito de la empresa. La galera además de ser el medio habitual para los comerciantes mediterráneos tenía mayor maniobrabilidad y estaba mejor preparada en caso de conflicto naval ${ }^{13}$. Se podría entonces establecer que las primeras naves fueron galeras, para abrir la ruta, y que, años más tarde cuando la ruta se conoce mejor, aparecieron también cocas. Independientemente de los riesgos del trayecto, la capacidad de carga de ambos tipos de barcos había aumentado considerablemente.

Por otra parte, otra de las cuestiones relativas a la rentabilidad de la navegación es la que se refiere a la duración del viaje. El comercio marítimo tradicional durante la Edad Media fue el de cabotaje, es decir, siguiendo la línea de costa. Una navegación de cabotaje hasta el Canal de la Mancha supondría aumentar enormemente la distancia del viaje en comparación con la ruta terrestre. Difícilmente podría ser rentable un trayecto tan largo, a menos que en cada parada los beneficios fueran altos ${ }^{14}$. A pesar de ello está constatado el cabotaje de comerciantes mediterráneos por las costas del Cantábrico ${ }^{15}$, algo que tampoco niega la posibilidad de que el trayecto hubiese sido realizado de forma directa o reduciendo considerablemente al menos el número de paradas. La navegación directa aun sin contar con instrumentos de referenciación astronómica era posible cuando la trayectoria del barco se hacía latitudinalmente puesto que los navegantes eran capaces de orientarse con la posición de los astros ${ }^{\mathrm{I}}$. Es más, los vientos del océano empujaban hacia el continente, reduciendo por tanto los riesgos de perderse en alta $\operatorname{mar}^{17}$. De esta forma, a priori parece sensato que existiendo la oportunidad

asume que las galeras genovesas soportaban mayores cargas que por ejemplo las venecianas, las cocas mediterráneas, una adaptación del kogge, tenían más capacidad de carga. BALARD, Michel: La romanie genovesa (XIle-début du XVe siècle). Roma, École française de Rome, Palais Farnese, 1978. p. 562.

11. Doehaerd, René: op. cit. p. 10.

12. Tuccl, Ugo: «Navi e navigazioni all'epoca delle crociate» en OrTALLI, Gherardo (et alii): Genova, Venezia, il levante nei secoli XII-XIV. Venecia, Istituto Veneto di Scienze, Lettere ed Arti, 2001, pp. 273-294. p. 283.

13. Ídem. p. 279. David Abulafia incide en que además la galera tenía más facilidades para salvar la corriente del Atlántico hacia el Mediterráneo gracias a los remos. AbuLAfIA, David: Un emporio mediterráneo... op. cit. pp. $231-232$.

14. Antonio Ortega Villoslada realiza un magnífico estado de la cuestión sobre cómo sería el trayecto, si a través del cabotaje o de forma directa. ORTEGA VilLosLAdA: Antonio. «Viaje a Flandes e Inglaterra... op. cit. p. 239.

15. En 1304, una fecha casi tres décadas después del primer viaje, se tiene noticia de barcos mallorquines en el norte de la península. AbulafiA, David. op. cit. p. 252.

16. Distintos autores señalan esta posibilidad: TANgheroni, Marco. Commercio... op. cit. p. 195; PARRY, John Horace: El descubrimiento del Mar. Barcelona, Grijalbo, 1986. p. 204. Antonio Ortega Villoslada afirma que incluso en el Mediterráneo, entre Mallorca y Cerdeña se navegaba por referenciación astronómica en aquélla época. ORTEGA VILLOSLADA, Antonio: «Viaje a Flandes e Inglaterra... op. cit. pp. 229-232.

17. Idem. p. 242. 
de navegar directamente se llevase a cabo, pero para poder afirmarlo es necesario antes atender a los posibles puntos de parada a lo largo de la ruta.

El espacio costero que abarca desde el Estrecho de Gibraltar hasta Flandes se puede dividir en tres ámbitos: el sur de la Península Ibérica, Portugal y Galicia, y el litoral cantábrico. El primero obligaba a resguardarse en alguno de los enclaves costeros a causa de las dificultades que ocasionaba cruzar el estrecho. Las paradas podían ser tanto antes como después y en ambos espacios existían mercados con una oferta amplia para la comercialización de bienes. Del lado Mediterráneo estaba el puerto de Málaga dentro del reino de Granada y la ciudad de Ceuta, frecuentados ambos por los cristianos para el paso del estrecho con anterioridad a la ruta atlántica ${ }^{\mathrm{I}}$. En el lado Atlántico Sevilla había sido también una parada habitual para afrontar el cruce del estrecho, y era además el principal puerto del suroeste de la Península Ibérica, como evidencian los múltiples acuerdos comerciales realizados entre los distintos poderes que se sucedieron con comerciantes de distintas nacionalidades ${ }^{19}$.

El litoral portugués y gallego no ofrecía tantas oportunidades de beneficio ni tampoco obligaba a realizar ninguna parada. No obstante, en este espacio no se puede diferenciar entre un viaje directo y el cabotaje porque la trayectoria de la ruta seguía la línea costera de modo que la única complicación es tratar de precisar en qué enclaves se podrían detener en caso de hacerlo. En el caso de que posteriormente sí que se realizase un viaje directo desde la costa gallega, el puerto de Ferrol serviría como última parada antes de empezar el tramo más largo sin avistar $\operatorname{costa}^{20}$. En cambio, el litoral portugués no parece haber registrado una actividad destacable ${ }^{2 \mathrm{I}}$ como para determinar un puerto como enclave habitual dentro de este itinerario.

El último de los tres ámbitos, el cantábrico, es el que arroja más luz sobre las posibilidades del viaje debido a que presenta una mayor distorsión entre un trayecto directo o de cabotaje. En este espacio existía una red integrada que abarcaba desde las costas gallegas hasta Flandes e Inglaterra que se articulaba a través del

18. Constable, Olivia Remi: Trade and traders in Muslim Spain. The commercial realignment of the Iberian Peninsula.900-1500. Cambridge, Cambridge University Press, 1994. p. 247. La ciudad de Ceuta ejerció una gran atracción a los comerciantes cristianos por sus riquezas en el siglo XIII, fruto de ello durante todo el siglo existen acuerdos con comerciantes de diferente procedencia. Idem. p. 42. Por otra parte, el reino de Granada llegaría a un acuerdo comercial en 1279 con Génova buscando una simbiosis comercial-política cuyo fin era garantizar la supervivencia del propio reino. FÁbreGAS GARCíA, Adela: «La integración del reino nazarí de Granada en el espacio comercial europeo (siglos XIII-XV)», Investigaciones en Historia Económica, nº 6, (2006), pp. 11-40. p. 17

19. Pistarino, Geo: «Presenze ed influenze italiane nel sud della Spagna (secc. XII-XV)» en Presencia italiana en Andalucía, siglos XIV-XVII. Actas I coloquio hispano italiano, Torres RamíreZ, Bibiano y Hernández Palomo, José (eds.). Sevilla, Escuela de Estudios Hispano Americanos, 1985, pp. 21-51. pp. 24-30.

20. Ferreira Priegue, Elisa: Galicia en el comercio marítimo medieval. La Coruña, Fundación Pedro Barrie de la Maza, 1988. p. 486

21. La integración portuguesa en las redes económicas de la Europa atlántica no sería significativa hasta el siglo XIV. MIRANDA, Flãvio: «Portugal y las redes mercantiles en la Europa atlántica a finales de la Edad Media» en CARVAJAL de la Vega, David; AÑíbarro Rodríguez, Javier y Vitores Casado, Imanol (eds.): Redes sociales y económicas en el mundo bajomedieval. Valladolid, Castilla Ediciones, 2001. p. 164. 
comercio de cabotaje ${ }^{22}$. No obstante, los productos que en ella se intercambiaban eran semejantes a los del Mediterráneo siendo difícil por tanto para los comerciantes provenientes del sur encontrar en este espacio un nicho comercial con el que introducirse en estos mercados ${ }^{23}$. Existen datos acerca de intercambios con operadores mediterráneos en estos espacios, pero estas empresas no tenían como destino el Canal de la Mancha ${ }^{24}$; los barcos que arribaban a estas costas dentro de la ruta atlántica lo hacían más bien por dificultades en la navegación antes que por posibilidades de mercado. En definitiva, la costa cantábrica no parece haber formado parte de la ruta atlántica ${ }^{25}$.

Respecto a los productos que se comercializaron, este es el tercer factor a considerar en la formación de esta nueva ruta. Como se ha mencionado anteriormente la ruta atlántica supone una alternativa a las rutas terrestres que se organizaban a través de las Ferias de Champaña; unas rutas que especializadas en los productos de la industria textil. Los principales productos de esta industria serían la lana y los tintes ${ }^{26}$. Ambas son materias primas fundamentales para la elaboración de los paños y además de gran volumen para su transporte. La mayor producción de lana provenía de Inglaterra y se dirigía hacia los Países Bajos y luego hasta las ciudades italianas, mientras que la mayor parte de los tintes provenían de diversos puntos del Mediterráneo y tomaban rumbo al norte.

La nueva ruta atlántica no alteraría esta relación bidireccional, sino que se adaptó a ella. En cierta medida, ya estaba adaptada y parte de la lana inglesa que llegaba hasta el Mediterráneo lo hacía por mar hasta el puerto de Gascuña y continuaba por tierra hasta Montpellier desde donde se embarcaba nuevamente hasta Mallorca para redistribuirla ${ }^{27}$. El principal producto que transportaron las primeras galeras en cruzar el estrecho hacia los Países Bajos fue alumbre ${ }^{28}$, realizando por tanto un intercambio comercial vinculado al textil.

Ahora bien, aunque este conjunto de factores hace posible la formación de la ruta atlántica, fueron en último término los comerciantes quienes tuvieron que vertebrar la ruta. Es aquí donde reluce el trabajo de Roberto López al vincular la

22. CHILDS, Wendy: Trade and Shipping in the Medieval West: Portugal, Castile and England. Porto, Fédération Internationale des instituts d’Études Médiévales, Gabinete de Filosofia Medieval, Faculdade de Letras, 2013. p. 79. A pesar de la afirmación de esta autora, autores como Ortega Villoslada aprecian en Las Partidas de Alfonso X una conexión habitual entre Sevilla y los puertos del Mar del Norte. ORTEGA VILLOSLADA, Antonio: El reino de Mallorca... op. cit. p. 199.

23. Ortega Villoslada, Antonio: «Viaje a Flandes e Inglaterra... op. cit. p. 239.

24. En 1296, cuando dos comerciantes mallorquines y uno genovés se mancomunan para llevar trigo desde Larache a La Rochela en vista de la carestía del cereal. ORTEGA VILLOSLADA: El reino de Mallorca... op. cit. p. 203.

25. HeERS, Jacques: Occidente durante los siglos XIV y XV. Barcelona, Labor, 1984. p. 145. Una opinión contraria a la aquí expuesta es la de Michel Mollat quien considera que la presencia de mercaderes italianos en las costas francesas indica una preparación logística de las rutas en las costas francesas del Cantábrico. MolLat du Jourdin, Michel: Europa y el Mar. Barcelona, Crítica, 1993. p. 69

26. La lana y el tinte fueron unos de los bienes más legislados por los monarcas y las ciudades. ReYERSON, Kathryn: «Commerce and communications» en ABULAFIA, David (ed.): The New Cambridge Medieval History. Volume V c. 1198-c. 1300. Cambridge, Cambridge University Press, 2008, pp. 50-70. pp. 57-60.

27. AbULAFIA, David: Un emporio mediterráneo... op. cit. p. 231.

28. DOeHAerd, René: op cit. p. 33. 
apertura de estas comunicaciones con Benedetto Zaccaria, marinero y comerciante genovés que recibió del imperio bizantino el control sobre las minas de alumbre de las islas de Quíos en $1264^{29}$. Al hacerse cargo de estas minas, que producían uno de los mejores mordientes en gran cantidad, empezó a buscar diferentes salidas a su comercialización apostando por nuevos espacios. Este fue el estímulo necesario para comenzar la actividad en la ruta atlántica.

Sin embargo, no se puede atribuir todo el éxito al comerciante genovés. Una commenda de 1274 revela cómo Benedetto Zaccaria indica a Oberto Mari y Pietro di Negri que transportasen el alumbre hasta Mallorca, y de ahí hasta donde «Dios lo permitiera $»^{30}$. Alrededor de este documento surge un debate sobre quienes fueron realmente los primeros operadores en adentrarse en la ruta atlántica, si mallorquines o genoveses. Roberto López lo interpreta como un intento de los genoveses de sacar provecho de los conocimientos mallorquines sobre las costas del Atlántico ${ }^{3 \mathrm{I}}$, a quienes finalmente superarían haciéndose con la hegemonía de la nueva ruta. No obstante, trabajos más recientes no conciben la relación entre unos y otros de forma competitiva, sino que muestran cómo se complementan a través de contratos en los que participan conjuntamente ${ }^{32}$.

En resumen, se aprecia que existieron una serie de oportunidades favorables en la navegación, en menor medida en la disponibilidad de mercados a lo largo del trayecto, y, en los productos para comercializar, que es aprovechada por los mercaderes para abrir una nueva vía que conecta dos de los principales espacios económicos de la Baja Edad Media.

\section{LA CONSOLIDACIÓN DE LA RUTA ATLÁNTICA. 1290-1320}

En la transición del siglo XIII al XIV las rutas del comercio del textil fueron parcialmente reorganizadas. A comienzos del siglo XIV la importación de lana inglesa en Florencia triplicó a la de I27333. Sin embargo, entre I298 y I320 las Ferias de Champaña, lugar de referencia para la distribución de lana hacia Italia, sufrieron una caída del tráfico de mercancías y de los beneficios ${ }^{34}$. ¿Siguió la lana inglesa

29. Sabatino López, Roberto: «Majorcans and Genoese... op. cit. p. 1177.

30. Idem. p. 1176 .

31. La presencia de mallorquines en las costas del Atlántico no está documentada hasta fechas posteriores a 1277. Sin embargo, David Abulafia a partir del mencionado contrato de commenda, la existencia de un comercio de cabotaje atestiguado durante los primeros años del siglo XIV, y el conocimiento cartográfico que tienen del Atlántico, propone que es probable que los contactos con esta zona fuesen asiduos con anterioridad a la ruta. ABULAFIA, David: Un emporio mediterráneo... op. cit. p. 237.

32. Idem. p. 234; ORTEGA VillosLada, Antonio: «Las relaciones marítimo-comerciales entre el Mediterráneo y el Atlántico. El papel de Mallorca en el comercio entre oriente y Occidente. Siglos XIV y XV», Memòries de l'Acadèmia Mallorquina d'Estudis Genealògics, n²0, (2010), pp. 61-80. pp. 71-72.

33. Sabatino López, Roberto: «Majorcans and Genoese... op. cit. p. 1168

34. EdWARds, Jeremy y OGILVILLE, Seilagh: «What lessons for economic development can we draw from the 
otros itinerarios terrestres o lo hizo principalmente por mar? No es fácil responder, pero resulta esclarecedor el paso del control de las exportaciones de manos flamencas a italianas a consecuencia de los conflictos entre Inglaterra y Flandes entre los años I294 y I29735. Más adelante, en I3i6 el rey Eduardo Il concierta el envío de trigo por parte de genoveses residentes en Sevilla ${ }^{36}$. La estabilidad de los intercambios a través ruta atlántica parece más que probable.

Las causas de la consolidación de la ruta se pueden remontar a la última década del siglo XIII, momento en el que Benedetto Zaccaria desplegó una intensa actividad política sobre los distintos puntos de la ruta. Si bien, hacia I277 la «Guerra del Estrecho» no supuso un obstáculo para atravesar del Mediterráneo al Atlántico, ya que los genoveses se mantuvieron al margen durante la primera etapa del conflicto, no así a partir de I285, cuando es nombrado comandante de la armada castellana Benedetto Zaccaria ${ }^{37}$. Aunque el contrato duró menos de un año, el genovés recibió como parte del pago la jurisdicción de El Puerto de Santa María, contando así con una excelente base de operaciones para comerciar en este eje norte-sur, y también para penetrar en las redes comerciales castellanas ${ }^{38}$. Benedetto Zaccaria sería nuevamente contratado entre I292 y I294, pero a partir de 1294 trabajó en la organización de la armada francesa ${ }^{39}$. Estos contratos sirvieron para acompañar con garantías políticas a la actividad comercial que años antes había iniciado.

Posteriormente, en la última década del siglo XIII, comenzaron a participar nuevos operadores con motivo del «repliegue hacia occidente», manifestado con claridad en I29i por la caída de Acre al limitar aun más las posibilidades comerciales en el Mediterráneo Oriental ${ }^{40}$. Dentro de este contexto, otros comerciantes seguirían un modelo similar al de los Zaccaria, buscando en los poderes políticos una forma de afianzar su posición en la ruta atlántica. Un ejemplo es el de la familia

\footnotetext{
Champagne fairs?», Explorations in Economic History, n 49, (2012), pp. 131-148. pp. 130-131. El trabajo de estos dos autores constituye un minucioso y actualizado estado de la cuestión sobre las fechas del declive y sus motivos.

35. LLOYd, Henry: The English wool trade in the Middle Ages. Cambridge, Cambridge University Press, 1977. p. 140.

36. Ortega Villoslada, Antonio: El reino de Mallorca... op. cit. p. 71.

37. Ladero Quesada, Miguel Ángel: op. cit. p. 268.

38. La familia Zaccaria afianzó su posición a través de matrimonios con la población local. D’ARIENZo, Luisa: «Le relazioni tra Genova e Cadice fra il XIII e il XV secolo.» en La península ibérica entre el Mediterráneo y el Atlántico; siglos XIII-XV. Cádiz, 1-4 de abril de 2003, González Jiménez, Manuel y Romero - Camacho, Isabel (eds.), Cádiz, Diputación de Cádiz, 2006, pp. 733-746. p.736.

39. DUARTE, Luis Miguel: «Zaccaria, Pessagno, Bocanegra: os almirantes genoveses nos primórdios das marinhas de guerra de Castela, Franca e Portugal» en GALLINARI, Luciano (ed.): Génova una «porta» del Mediterraneo. Génova, Instituto di Storia dell'Europa Mediterranea, 2005. p.282.

40. Riera Melis, Antoni: «El context mediterrani de la primera fase del regnat de Jaume II (1291-1311): conflictivitat i canvis», Anales de la universidad de Alicante. Historia Medieval, nº 12, (1999), pp. 183- 205. p. 183. En un marco cronológico más amplio se habla de un «repliegue hacia Occidente» desde el siglo XII. AIRALDI, Gabriella. «Les Italiens et l'Océan à la fin du Moyen Age» en L'Europe et l'Océan au moyen âge. Contribution à l'histoire de la navigation, Société des historiens médiévistes de l'enseignement supérieur. Paris, C.I.D. Editions, 1988, pp. 183-205. p. 112-113. PHILLIPS, John Roland: The medieval expansion of Europe. Oxford, Oxford University Press, 1988. p. 157. PARRY, John Horace: op cit. p. 253; Un trabajo más reciente que trata este tema es el de ABULAFIA, David: «ltalia e lo spostamento economico del XV secolo», en AURELL, Jaume, (ed.): El Mediterráneo medieval y renacentista, espacio de mercados y culturas. Pamplona, EUNSA, 2002, pp 172-212.
} 
Pessagno, natural de Génova, que entró en las redes comerciales atlánticas primero en Inglaterra a través de la concesión de préstamos al monarca hacia $\mathrm{I}_{3} \mathrm{IO}^{4 \mathrm{I}}$, y seis años más tarde ocupando Manuel Pessagno el cargo de almirante mayor de la armada portuguesa ${ }^{42}$. Pero también destaca, sin alianzas políticas formales en el trayecto, el establecimiento de una línea comercial marítima con el norte de Europa por parte de los venecianos en la segunda década del siglo XIV ${ }^{43}$, y un incremento en la documentación de la presencia de comerciantes mallorquines ${ }^{44}$. Da esto cuenta del atractivo de la nueva ruta, la que fue transitada en sus comienzos por comerciantes mediterráneos, pero no atlánticos.

\section{LA RUTA ATLÁNTICA EN EL SIGLO XIV}

La navegación, los puertos y los productos comercializados que permitieron apostar por la ruta atlántica a finales del siglo XIll y comienzos del XIV se vieron transformados, a su vez, por el aumento del tráfico marítimo y comercial. Esto dio pie a nuevas ventajas, retroalimentando la dinámica comercial ${ }^{45}$.

Respecto a la navegación, el siglo XIV no plantea un debate entre qué barco ofrecía más ventajas en cuanto a capacidad de carga y seguridad, la coca se convirtió en la embarcación habitual entre los comerciantes mediterráneos ${ }^{46}$. Entre las ventajas que ofrecía las más importantes eran el menor coste de construcción, y la relación de marineros por tonelada -la clave residía en no necesitar remeros-, pasándose de un hombre por cada cinco toneladas en el siglo XIII a uno por cada diez en el XIV47. Esto no resta a que siguieran surcando la ruta las galeras, como fue en el caso de la línea regular veneciana, porque durante el siglo XIV el tamaño de los barcos continuó en aumento ${ }^{48}$. También, queda constatada la capacidad de realizar el trayecto de forma directa desde las costas gallegas hasta el Canal de la Mancha al existir evidencias de ello en los viajes de comerciantes portugueses ${ }^{49}$.

Por otro lado, los enclaves de la ruta se multiplicaron, aumentando el número de puertos referencia y especializándose según el origen de los operadores que en

41. BASSO, Enrico: «I genovesi in Inghilterra fra tardo medioevo e prima Etá Moderna» en GALLINARI, Luciano (ed.) Genova, una «porta» del Mediterraneo. Genova, Brigati, 2005, pp. 524-574. p. 534.

42. DUARTE, Luis Miguel: op. cit. p. 286.

43. LóPEZ de COCA CASTAÑ̃R, José Enrique: «Las galeras venecianas de Poniente y Berbería desde la perspectiva española», Medievalismo: boletín de la Sociedad Española de Estudios Medievales, nº 16, (2006), pp. 113-172. p. 114.

44. Antonio Ortega Villoslada habla de los años de esplendor para el comercio mallorquín en la ruta atlántica entre las fechas 1326-1330. ORTEga VillosLadA, Antonio: El reino de Mallorca... op. cit. p. 217.

45. Las consecuencias del desarrollo de la ruta presentan la dificultad interpretativa de verse acompañadas con una serie de cambios cualitativos en el comercio del siglo XIV que han sido estudiados fundamentalmente para el caso de la península ibérica. IGUAL LUIS, David: «¿Crisis? ¿Qué crisis? El comercio internacional en los reinos hispánicos de la Baja Edad Media», Edad Media, Revista de Historia, n8, (2007), pp. 203-223. p. 209.

46. En palabras de Ugo Tucci fue la «nave del siglo». TucCl, Ugo: op. cit. p. 283-285.

47. TAngheroni, Marco: Commercio... op. cit. p. 206.

48. Idem. p. 199.

49. CHILDS, Wendy: op. cit. p. 104 
ellos comerciaban. Siguiendo por orden los tres ámbitos: el sur de la Península Ibérica, Portugal y Galicia, y el litoral cantábrico, se aprecia una mayor integración en los sistemas comerciales de cada espacio. Comenzando por el reino de Granada, al puerto de Málaga se le sumó el de Almería en la derrota del Mediterráneo al Atlántico. Mientras que Granada continuó siendo el principal puerto para los genoveses, el de Almería lo sería para los comerciantes catalanes ${ }^{50}$. Al otro lado del Estrecho de Gibraltar se trasladó la referencia portuaria de Sevilla hacia Cádiz y El Puerto de Santa María, evitando de esta forma remontar el Guadalquivir ${ }^{51}$. Esto no supuso una pérdida de funciones del puerto de Sevilla que continuó siendo uno de los principales ${ }^{52}$, sino que los territorios del valle del Guadalquivir lograron una fuerte integración económica ${ }^{53}$, no sólo por la rica producción del territorio sino además por la capacidad de captación de productos de diversos orígenes, especialmente del Norte de África ${ }^{54}$.

En segundo lugar, en el litoral portugués se aprecia un incremento de la actividad comercial con el asentamiento de mercaderes extranjeros en el siglo XIV55. Sin embargo, los puertos portugueses no ejercieron tanto poder de atracción como los del sur de la península. Prueba de ello son las cartas del agente comercial de la familia Alberti enviado a Lisboa en $1399^{56}$, o la escasa presencia de otros comerciantes habituales de la ruta como los catalanes ${ }^{57}$.

Finalmente, el litoral cantábrico no se permeó a los comerciantes mediterráneos hasta finales del siglo XIV, cuando comenzaron a ser más frecuentes los intercambios con estas $\operatorname{costas}^{58}$. Una buena imagen para resumir la importancia de los tres ámbitos dentro de la ruta atlántica la otorga el manual comercial del florentino Francesco Balduci Pegolotti de entre I3I0 y I340, que se centra fundamentalmente

50. Fábregas García, Adela: «La integración del reino... op. cit. pp. 17 y 22. El puerto de Almería había sido hasta el inicio de la ruta atlántica el principal puerto del reino, pero luego sería relegado por el de Málaga donde a finales del siglo XIV empezaron a llegar comerciantes florentinos y venecianos.

51. D'ARIEnzo, Luisa: op. cit. p. 737. El Puerto de Santa María sería más próspero que el de Cádiz en el siglo XIV. GonZÁlez JIMÉNEZ, Manuel: «Cádiz en el siglo XIII: Historia de un proyecto frustrado» en La Península Ibérica entre el Mediterráneo y el Atlántico; siglos XIII-XIV. Cádiz, 1-4 de abril de 2003, GonZÁlez JIMÉneZ, Manuel y Romero - CamaCho, Isabel (eds.), Cádiz, Diputación de Cádiz, 2006. pp. 747-758. p. 757.

52. Aznar Vallejo, Eduardo: «Andalucía y el Atlántico norte a fines de la Edad Media», Historia Instituciones Documentos, $\mathrm{n}^{\circ}$ 30, (2003), pp. 103-120. pp. 104-105.

53. D'ARIENZO, Luisa: op. cit. p. 738.

54. Aznar Vallejo, Eduardo: op cit. p. 111.

55. Los primeros en arribar fueron los comerciantes ingleses, y tras la llegada de los Pessagno llegaron comerciantes italianos. CHILDS, Wendy: op. cit. p. 119; SoldANI, María Elisa: «Dal Mediterraneo all'Atlantico. Gli uomini d'affari fiorentini nella Penisola Ibrica tra Tre e Quattrocento», en Vespucci, Firenze e le Americhe. Atti del convegno di studi, Firenze, 22-24 novembre 2012, PINTO, Giuliano; RomBAI, Leonardo y TRIPODI, Claudio (coords.), Florencia, Leo S. Olschki Editore, 2014, p. 43- 72. p. 46.

56. Idem. pp. 50-51.

57. Desportes Bielza, Pablo: «El consulado catalán de Brujas (1330-1488)», Aragón en la Edad Media, nº 14-15, (1), (1999), pp. 375-390. p. 379.

58. ORTEGA VILlos LAdA, Antonio: «Viaje a Flandes e Inglaterra... op. cit. p. 239. Es en el siglo XV cuando los puertos de la costa cantábrica de la península desarrollan sus principales infraestructuras SolórZANO TeLECHEA, Jesús Ángel: «Medieval Seaports of the Atlantic Coast of Spain», International journal of maritime history, Vol. 21, $\mathrm{n}^{\circ}$. 1, (2009), pp. 81-100. pp. 95-97. 
en los puertos del sur de la península, algo menos en la costa portuguesa y apenas en el litoral cantábrico ${ }^{59}$.

En cuanto a los productos comercializados entre el Mediterráneo y el Atlántico, el alumbre y la lana continuaron siendo los principales, pero en los viajes hacia el norte se incluyeron además otros como fruta, azúcar, vino, aceite, arroz, almendras, azafrán, algodón, telas de lujo, y otras manufacturas, las cuales procedían en gran medida del sur peninsular ${ }^{60}$. En cambio, en dirección sur se incluiría en menor medida plomo y estaño inglés, y pieles y metales del báltico ${ }^{6}$. El transporte de estos nuevos productos en las bodegas de los barcos muestra una integración de los territorios de la ruta en la misma, que es nuevamente fruto de la habilidad de los operadores a la hora de sacar provecho a las oportunidades que la ruta ofrecía.

Durante el siglo XIV las familias genovesas, que habían conseguido una situación ventajosa a partir del acercamiento a los poderes políticos que controlaban los enclaves de la costa, aumentaron la rentabilidad de la ruta al conectar el comercio local con el internacional. De esta forma, existían explotaciones agrícolas en el valle del Guadalquivir orientadas al comercio exterior ${ }^{62}$, así como en Granada la familia Spínola mantenía el monopolio del azúcar y las frutas secas para la exportación y vendía mercancías del norte de Europa al interior del reino ${ }^{63}$. El ensamblaje de un mercado y otro sería continuado posteriormente por nuevos operadores que participaron en la ruta como los florentinos ${ }^{64}$, o nuevas familias genovesas como los Lomellini en Portugal ${ }^{65}$.

Por otro lado, los operadores en la ruta se multiplicaron en el siglo XIV. No sólo se encuentran atravesando el estrecho los mediterráneos, sino que a también lo hacen los atlánticos. En el estudio sobre el comercio del reino de Mallorca de Antonio Ortega Villoslada, se observa la presencia de mercaderes vascos, cántabros y portugueses en las islas ya durante la primera mitad del siglo $\mathrm{XIV}^{66}$. No

59. Pistarino, Geo: op. cit. pp. 38-39.

60. Guidi Bruscolı, Francesco. «I rapporti con il Nord-Europa», en Nigro, Giampiero (coord.): Francesco di Marco Datini. L'uomo, il mercante. Florencia, Fondazione di Instituti di Storia Economica F. Datini, 2010. p. 417.

61. Ibid. p. 421.

62. Por otra parte, incluso existían explotaciones de aceite cuya producción estaba orientada directamente hacia el comercio exterior. GonzÁLEZ JIMÉNEZ, Manuel: «Genoveses en Sevilla (Siglos XIII-XV)» en Presencia italiana en Andalucía, siglos XIV-XVII. Actas I coloquio hispano italiano, Torres Ramírez, Bibiano y Hernández Palomo, José (eds.), Sevilla, Escuela de Estudios Hispano Americanos, 1985, pp. 115-130. p. 125.

63. Fábregas García, Adela y García Porras, Alberto: «Redes mercantiles genovesas en el sur de la península ibérica. Circulación mercantil y transferencias productivas» en del VAL VALDIVIESO, María Isabel y MARTínez SOPENA, Pascual (eds.): Castilla y el mundo feudal. Homenaje al profesor Julio Valdeón. Valladolid, Junta de Castilla y León, Consejería de Cultura y Turismo, 2009. p. 641.

64. MELIS, Federigo: «La participación toscana en la navegación atlántica» en Las rutas del Atlántico, Trabajos del Noveno Coloquio Internacional de Historia Marítima (Sevilla, 24-30 Septiembre 1967) Coloquio Internacional de Historia Marítima, Sevilla, Escuela de Estudios Hispanoamericanos, 1969, pp. 281-293. p. 284.

65. El caso de los Lomellini es paradigmático puesto que introducen plantaciones de azúcar para su exportación. CHILDS, Wendy: op. cit. p. 68.

66. Ortega Villoslada, Antonio: El reino de Mallorca... op. cit. p. 260-262. 
obstante, la importancia de estos operadores en el Mediterráneo llegaría fundamentalmente en el $\mathrm{XV}^{67}$.

La primacía de la actividad de los comerciantes mediterráneos en la ruta durante los primeros siglos ha dado lugar a referirse a la apertura de esta ruta como una «iniciativa mediterránea», la cual transformaría los espacios económicos intermedios ${ }^{68}$. Sin embargo, la historiografía reciente manifiesta la complejidad de las operaciones comerciales reivindicando también el papel de los operadores locales. Ejemplos como el de la familia Spínola en el reino de Granada muestran una actividad comercial complementada con la de mercaderes granadinos, hablando así de unas relaciones de interacción e integración, por lo que se puede considerar que la formación de la ruta responde a un modelo de crecimiento polinuclear y no unidireccional ${ }^{69}$. Desde este segundo punto de vista, la ruta se consolidó en el siglo XIV no sólo como una vía entre dos centros económicos sino integrando gran parte de los nuevos territorios al sistema comercial europeo bajomedieval.

\section{EL IMPACTO DE LA RUTA ATLÁNTICA}

Las principales consecuencias que se pueden atribuir a la apertura de la ruta atlántica tienen que ver con las relaciones comerciales norte-sur, y con nuevas posibilidades de interpretación de la época de los descubrimientos.

Respecto al principal eje comercial del continente, diversos autores han atribuido a estos contactos marítimos el declive de las Ferias de Champaña y, en definitiva, una superación de los medios terrestres. Según Roberto López, quien inició la investigación sobre esta nueva ruta, la posibilidad del contacto directo por vía marítima entre los principales centros comerciales supuso un salto cualitativo con el establecimiento de «oficinas comerciales» que redujo los costes de mercado al haber menos intermediarios ${ }^{70}$. Sin embargo, esta idea, aunque compartida por muchos autores hasta la actualidad ${ }^{71}$, no presta mucha atención, ni

67. Mollat du Jourdin, Michel: op cit. p. 100. Un ejemplo concreto, los portugueses, aunque sea probada su presencia en el siglo XIV, no será hasta el siglo XV cuando su actividad comercial denote importancia. MUÑOz POMER, María Rosa; NAVARro EsPINACH, Germán e IGUAL LUIS, David: «El comercio portugués en el Mediterráneo Occidental durante la Baja Edad Media» en La Península Ibérica entre el Mediterráneo y el Atlántico; siglos XIII-XIV. Cádiz, 1-4 de abril de 2003, González Jiménez, Manuel y Romero - Camacho, Isabel (eds.), Cádiz, Diputación de Cádiz, 2006. pp. 73-84. p. 77.

68. TANGHeroni, Marco: «Rapporti economici tra il Mediterraneo el'Europa settentrionale», Revista d'historia Medieval, nº 6, (1995), pp. 53-62. p. 58. HeErs, Jacques: op. cit. p. 145.

69. Las relaciones entre comerciantes autóctonos y extranjeros fueron de interacción e integración, lo que define la idea de comercio polinuclear. Fábregas García, Adela y García Porras, Alberto: op. cit. p. 641.

70. Sabatino López, Roberto: La revolución comercial en la Edad Media. Barcelona, El Albir, 1982.

71. Pounds, Norman: Historia económica de la Europa Medieval. Barcelona, Crítica, 1987. p. 417; BerNARD, Jacques: «Comercio y finanzas en la Edad Media. 900-1500» en CIPolLA, Carlo (ed.): La economía de Europa. 1, La Edad Media. Barcelona, Ariel, 1987. p. 320; CONSTABLE, Olivia Remi: Trade and traders in Muslim Spain... op. cit. p. 245; TANGHERONI, Mario: «Rapporti economici... op. cit. p. 57; MANONNI, Tiziano: La rivoluzione mercantile nel Medioevo: uomini, merci e strutture degli scambi nel Mediterraneo. Genova, II Portolano, 2009. p. 77. 
explica el auge del transporte terrestre y de ferias de carácter internacional desde mediados del siglo XV hasta comienzos del XVII ${ }^{72}$.

La conexión marítima entre el Mediterráneo y el Atlántico no produjo transformaciones cualitativas en el conjunto de relaciones comerciales norte-sur. No supuso el declive de las Ferias de Champaña, a pesar de que a partir de la última década del siglo XIV menguó notablemente el volumen de intercambios. La cronología que sí se ajusta a la decadencia de estas ferias es la del conflicto franco-flamenco, que afectaba al territorio de forma directa y, en especial, a los mercaderes flamencos que acudían a ellas ${ }^{73}$. Otra prueba de que la ruta comercial no reconfiguró cualitativamente el comercio es la proliferación de ferias en el siglo XV. Las ferias, como espacios dedicados al intercambio, ofrecían ventajas para el desarrollo del comercio en relación a circulación de la información y la distribución de los productos que las convierten en un elemento necesario, que no pudo ser suplantado en el corto y medio plazo $^{74}$. Para algunos autores como Epstein las ferias, de hecho, fueron: «la columna vertebral de la economía premoderna» ${ }^{75}$. En definitiva, más que interpretar la aparición de esta ruta como una competencia entre medios marítimos y terrestres, habría que situarla en el contexto bajomedieval como una alternativa. Es decir, era un medio a considerar dentro de las estrategias de comercialización de los productos por los operadores o ante problemas coyunturales como pueden ser guerras o bloqueos políticos, que sucedían en tierra, pero, sin olvidar, que también sucedieron por mar.

Por otro lado, las perspectivas sobre la navegación ultramarina europea se dividen entre quienes la relacionan con el Renacimiento, y aquéllos que ahondan en los precedentes medievales. La primera tendencia está marcada en sus orígenes por la historia colonial, ya que se focaliza en las consecuencias de los «descubrimientos»; la formación de imperios que dominan vastos territorios, y también la formación de una nueva mentalidad ${ }^{76}$. El siglo XV es para estos autores el punto

72. MunRo, John: «The Low Countries' export trade in textiles with the Mediterranean basin, 1200-1600: a costbenefit analysis of comparative advantages in overland and maritime trade routes», International journal of maritime history, $\mathrm{n}^{\circ} 11$, (1999), pp. 1-30. pp. 8-11.

73. EdWARDS, Jeremy y OGILVILLE, Seilagh: op. cit. p. 139.

74. Douglass North y Robert Thomas consideran que lo lógico dentro del sistema comercial norte-sur es que las Ferias de Champaña se hubiesen mantenido o en todo caso trasladado hacia otro lugar estratégico. NORTH, Douglass Cecil y THOMAS, Robert Paul: El nacimiento del mundo occidental, una nueva historia económica (900-1700). Madrid, Siglo Veintiuno de España, 1978. pp. 91-92; Es de especial interés la representación gráfica del modelo evolutivo de los mercados que plantean Bruno Blonde, Peter Stabel e llja Van damme. BLondÉ, Bruno; STABEL, Peter y VAN DAMmE, Ilja: «Retail circuits and practices in medieval and early modern Europe: An introduction» en BLONDÉ, Bruno (et alii): Buyers \& sellers: retail circuits and practices in mediaeval and early modern Europe. Turnhout, Brepols, 2006. p. 7-30. p. 13.

75. Epstein, Stephan. Libertad y crecimiento. El desarrollo de los estados y de los mercados en Europa, $1300-1750$. Valencia, Publicaciones de la Universitat de València, 2009. p. 105.

76. Amuir, Ramsay. The expansion of Europe. The culmination of Modern History. Londres, Constable and Company S.L., 1922; Penrose, Boies: Travel and Discovery in the Renaissance (1420-1620). Cambridge, Harvard University Press, 1952; Cipolla, Carlo: Cañones y velas. Las bases del predominio europeo en el mundo (1400-1700). Barcelona, Ariel, 1967. La mayoría de los trabajos de historia colonial analizan los descubrimientos como una consecuencia del «espíritu renacentista», siendo una excepción el de Elliot, que habla de un proceso de asimilación por el que hay una influencia bilateral. ElLIOT, John Huxtable: El Viejo Mundo y el Nuevo (1492-1650). Madrid, Alianza Editorial, 1972 
de partida de estos procesos ${ }^{77}$. En sentido opuesto están los estudios dedicados a señalar los rasgos medievales que perviven o impulsan estos viajes. Estos trabajos plantean una problemática de corte nacionalista caracterizada, en opinión de Francis Rogers, por la glorificación de «ser el primero en navegar en el Atlántico, rodear un cabo o descubrir un archipiélago...» $\rangle^{8}$. Pese a ello, abundan los trabajos libres de este tipo de ambiciones, y que, singularizando el siglo XV como punto de partida de una nueva dinámica expansiva, establecen referentes e indicios en épocas anteriores.

La figura de Marco Polo fue la que abrió este tipo de estudios ${ }^{79}$, tanto por las descripciones fantásticas como por su vocación comercial. Las imágenes fantásticas sobre el fasto oriental, islas o territorios llenos de riquezas, etc., sirvieron de acicate para embarcarse en empresas arriesgadas ${ }^{80}$, además de pervivir en la mentalidad de los primeros conquistadores ${ }^{81}$. Por otra parte, la búsqueda de nuevas rutas es un claro nexo con siglos precedentes de expansión económica. Sin embargo, los autores divergen a la hora de relacionarlo con el periodo de expansión económica, siendo una consecuencia tardía de dicha expansión ${ }^{82}$, o con el periodo de crisis medieval ${ }^{83}$. En cualquier caso, en estos trabajos resalta como trascendental el encuentro entre las tradiciones navales mediterránea y atlántica, propiciatorias del desarrollo técnico que hizo posible el éxito de los viajes del siglo XV.

Bajo estas últimas perspectivas, el desarrollo de la ruta atlántica se puede concebir como un precedente al dar forma a la base del éxito del XV. Esto se debe a que facilita dos requisitos que son señalados comúnmente: la creación de navíos preparados propiamente para el atlántico -fruto del encuentro entre de las dos tradiciones navales y una experiencia continuada de navegación en aguas oceánicas-, y el liderazgo portugués y castellano -fomentado desde el ámbito económico por su inserción dentro de las redes comerciales internacionales. Si bien, esto es una influencia indirecta, hay autores que también afirman un impacto directo. Pierre Chaunu, compara, a escala mediterránea, la apertura del Estrecho de Gibraltar con la aventura de Vasco da Gama, fundamentalmente porque seguidamente

77. La historia colonial también se ha extendido al ámbito medieval, pero con una menor repercusión dada la controversia que genera el término de «imperios marítimos» al compararla con el concepto medieval de imperio y con los imperios ultramarinos de épocas posteriores. SCAMmELL, Geoffrey Vaughan: The World Emcompassed: The First Maritime Empires, c. 800-1650, Berkley, University of California Press, 1981.; Fernández-Armesto, Felipe: Antes de Colón. Exploración y colonización desde el Mediterráneo hacia el Atlántico, 1229-1492. Madrid, Cátedra, 1993.

78. Rogers, Francis M.: «The Vivaldi Expedition», Annual Report of the Dante Society, with Accompanying Papers, $n^{\circ} 77$, (1955), pp. 31-45. p. 31.

79. Bezelay, Raymond: «Marco Polo and the european expansion of the Middle Ages», The Atlantic Monthly, $\mathrm{n}^{\circ}$ 104 (1909), pp. 493-501..

80. PHILlips, John Roland: The Medieval Expansion of Europe. Oxford, Oxford University Press, 1988.

81. WECKMAN, Luis: «The middle ages in the discovery of America», Speculum, 26 (1), (1951), pp. 130-141.; HYDE, John Kenneth. «Real and imaginary journeys in the later middle ages», Bulletin of the John Rylands Library, Vol. 65, (1982/83), pp. 125-147.

82. Chaunu, Pierre: La expansión europea (siglos XIII al XV). Barcelona, Labor, 1982; AdÃo da FonseCA, Luís: Dal Mediterraneo all'Atlantico. Le scoperte e la formazione nei secoli XIV-XVI. Cagliari, Consiglio Nazionale delle Ricerche, 2004.

83. PARRY, John Horace: El descubrimiento del mar. Barcelona, Crítica, 1989. 
hubo otros episodios más ambiciosos como el de los hermanos Vivaldi en I29I buscando una ruta con Asia por el Atlántico ${ }^{84}$. No obstante, aunque es posible que al establecerse la ruta atlántica hubiese una mayor confianza en las capacidades navieras de la época, no es comparable a un referente como el de Marco Polo. La principal diferencia reside en que, en aquella época, los horizontes míticos tenían una proyección más poderosa y duradera que otros hitos que contribuyesen a expandir las conexiones marítimas.

\section{CONCLUSIONES}

Los inicios de la ruta atlántica, y su desarrollo, responden a la capacidad de los comerciantes -concretamente la de los mediterráneos y más precisamente la de los genoveses- para manejar las posibilidades que ofrece su entorno y a través de ellas establecer nuevas plataformas para los intercambios. Dicha capacidad no surge, para este caso, de una concepción global del sistema comercial, sino del provecho de unas circunstancias concretas como es la concesión de las minas de Focea, aunque también tiene una perspectiva más amplia. Benedetto Zaccaria dirige sus mercancías hacia los comerciantes mallorquines porque pueden ser útiles para arribar las costas del norte de Europa, o la familia Pessagno se aproxima a casas reales estratégicas en el trayecto.

En referencia a esto último, el desarrollo de esta ruta muestra que la lectura de las oportunidades económicas está acompañada de una aproximación política. La acción mercantil está entrelazada con otras como las militares o bancarias, útiles para atraer el favor real, como nos muestran ambos casos, Zaccaria y Pessagno, y también otros. Sería interesante hacer un análisis inverso a este, uno con el que interpretar la acción política a partir de los movimientos económicos. Aquí proponemos uno, la «Guerra del Estrecho» las relaciones diplomáticas a partir de los intereses comerciales de las diferentes potencias implicadas.

Finalmente, del lado de las consecuencias de la ruta, la principal es que trae consigo nuevas oportunidades lucrativas, integrando un espacio periférico del comercio europeo. No es tan importante el debate referido a las Ferias de Champaña, sino la flexibilidad que se muestra al desdoblarse el principal eje incluyendo nuevos espacios que se integrarían en el conjunto del sistema. Esta integración repercute igualmente, de forma indirecta, sobre los viajes de «descubrimiento» del siglo XV.

\footnotetext{
84. Chaunu, Pierre: op cit. p. 37
} 


\section{BIBLIOGRAFÍA}

Abulafia, David: Un emporio mediterráneo: el reino catalán de Mallorca. Barcelona, Omega, I996.

AbUlAFIA, David: «Italia e lo spostamento economico del XV secolo», en Aurell, Jaume, (ed.): El Mediterráneo medieval y renacentista, espacio de mercados y culturas. Pamplona, EUNSA, 2002, pp. I79-212.

ADÃo da Fonseca, Luís: Dal Mediterraneo all'Atlantico. Le scoperte e la formazione nei secoli XIV-XVI. Cagliari, Consiglio Nazionale delle Ricerche, 2004.

AlrAldi, Gabriella. «Les Italiens et l'Océan à la fin du Moyen Age» en L'Europe et l'Océan au moyen âge. Contribution à l'histoire de la navigation, Société des historiens médiévistes de l'enseignement supérieur. Paris, C.I.D. Editions, I988, pp. I83-205.

AmulR, Ramsay. The expansion of Europe. The culmination of Modern History. Londres, Constable and Company S.L., I922.

ARChibald, Lewis: «Northern sea power and Gibraltar» en ARCHibald, Lewis: The sea and medieval powers. Collected studies. London, Variorum Reprints, I978. p. IIo.

Aznar Vallejo, Eduardo: «Andalucía y el Atlántico norte a fines de la Edad Media», Historia Instituciones Documentos, $\mathrm{n}^{\mathrm{o}}$ 30, (2003), pp. I03-I20.

BALARD, Michel: La romanie genovesa (XIle-début du XVe siècle). Roma, École française de Rome, Palais Farnese, I978.

Balard, Michel: La Méditerranée médiévale: Espaces, itinéraires, comptoirs. Paris, Picard, 2006.

BASso, Enrico: «I genovesi in Inghilterra fra tardo medioevo e prima Etá Moderna» en Gallinari, Luciano (ed.) Genova, una «porta» del Mediterraneo. Genova, Brigati, 2005, pp. 524-574.

BAUTIER, Robert Henri: «Les foires de Champagne. Recherches sur une évolution historique». Recueils de la Société Jean Bodin, $\mathrm{n}^{\circ}$ 5, (I953), pp. 97-I47.

BERNARD, Jacques: «Comercio y finanzas en la Edad Media. 900-I500» en Cipolla, Carlo (ed.): La economía de Europa. I, La Edad Media. Barcelona, Ariel, I987, pp. 295-36I.

Bezelay, Raymond. «Marco Polo and the european expansion of the Middle Ages.», The Atlantic Monthly, $\mathrm{n}^{\mathrm{O}}$ I04 (1909), pp. 493-50I.

Blondé, Bruno; Stabel, Peter y Van Damme, Ilja: «Retail circuits and practices in medieval and early modern Europe: An introduction» en BLONDÉ, Bruno (et alii): Buyers \& sellers: retail circuits and practices in mediaeval and early modern Europe. Turnhout, Brepols, 2006. p. 7-30.

Chaunu, Pierre: La expansión europea (siglos XIII-XV). Barcelona, Labor, I972.

CHILDS, Wendy: Trade and Shipping in the Medieval West: Portugal, Castile and England. Porto, Fédération Internationale des instituts d'Études Médiévales, Gabinete de Filosofia Medieval, Faculdade de Letras, 2013.

Cipolla, Carlo: Cañones y velas. Las bases del predominio europeo en el mundo (I400-I70o). Barcelona, Ariel, I967.

CONSTABle, Olivia Remi: At the edge of the west: International trade and traders in Muslim Spain (IOOO-I250). Ann Arbor, University Microfilms International, I989. pp. IO2-II5.

Constable, Olivia Remi: Trade and traders in Muslim Spain. The commercial realignment of the Iberian Peninsula.900-I500. Cambridge, Cambridge University Press, 1994.

D'ARIEnZo, Luisa: «Le relazioni tra Genova e Cadice fra il XIII e il XV secolo.» en La península ibérica entre el Mediterráneo y el Atlántico; siglos XIII-XV. Cádiz, I-4 de abril de 2003, 
González Jiménez, Manuel y Romero-Camacho, Isabel (eds.), Cádiz, Diputación de Cádiz, 2006, pp. 733-746.

Desportes Bielza, Pablo: «El consulado catalán de Brujas (I330-I488)», Aragón en la Edad Media, $\mathrm{n}^{\mathrm{O}}$ I4-I5, (I), (I999), pp. 375-390.

DOEHAERD, René: «Les galères génoises dans la Manche et la Mer du Nord à fin du XIII et au début du XIV siècles» Bulletin de L'Institut Historique Belge de Rome, $\mathrm{n}^{\circ}$ I9, (I938), pp. 5-76.

Duarte, Luis Miguel: «Zaccaria, Pessagno, Bocanegra: os almirantes genoveses nos primórdios das marinhas de guerra de Castela, Franca e Portugal» en GAllinARI, Luciano (ed.): Génova una «porta» del Mediterraneo. Génova, Instituto di Storia dell'Europa Mediterranea, 2005, pp. 259-294.

EDWARds, Jeremy y OGILville, Seilagh: «What lessons for economic development can we draw from the Champagne fairs?», Explorations in Economic History, $\mathrm{n}^{\circ} 49$, (2012), pp. I3I-I48.

EpSTEIN, Stephan. Libertad y crecimiento. El desarrollo de los estados y de los mercados en Europa, I300-I750. Valencia, Publicaciones de la Universitat de València, 2009.

FÁBREGAS GARCíA, Adela: «La integración del reino nazarí de Granada en el espacio comercial europeo (siglos XIII-XV)», Investigaciones en Historia Económica, nº 6, (2006), pp. II-40.

FÁbregas García, Adela y García Porras, Alberto: «Redes mercantiles genovesas en el sur de la península ibérica. Circulación mercantil y transferencias productivas» en del VAL Valdivieso, María Isabel y Martínez Sopena, Pascual (eds.): Castilla y el mundo feudal. Homenaje al profesor Julio Valdeón. Valladolid, Junta de Castilla y León, Consejería de Cultura y Turismo, 2009, pp. 639-655.

Fernández-Armesto, Felipe: Antes de Colón. Exploración y colonización desde el Mediterráneo hacia el Atlántico, I229-I492. Madrid, Cátedra, I993.

Ferreira Priegue, Elisa: Galicia en el comercio marítimo medieval. La Coruña, Fundación Pedro Barrie de la Maza, I988.

Ferreira Priegue, Elisa: «Castilla: La génesis de una potencia marítima de Occidente», en Itinerarios Medievales e identidad hispánica. XXVII Semana de Estudios Medievales. Estella, i7-2i Julio 200, Ferreira Priegue, Elisa (et alii), Pamplona, Fondo de publicaciones del Gobierno de Navarra, 200I. pp. 23-46.

GonZÁlez JimÉnez, Manuel: «Genoveses en Sevilla (Siglos XIII-XV)» en Presencia italiana en Andalucía, siglos XIV-XVII. Actas I coloquio hispano italiano, Torres RamíreZ, Bibiano y Hernández Palomo, José (eds.), Sevilla, Escuela de Estudios Hispano Americanos, I985, pp. II5-I3O.

GonZÁlez JimÉnEZ, Manuel: «Cádiz en el siglo XIII: Historia de un proyecto frustrado» en La Península Ibérica entre el Mediterráneo y el Atlántico; siglos XIII-XIV. Cádiz, I-4 de abril de 2003, GonZÁlez Jiménez, Manuel y Romero - CAMACHo, Isabel (eds.), Cádiz, Diputación de Cádiz, 2006. pp. 747-758.

Guidi Bruscoli, Francesco. «I rapporti con il Nord-Europa», en Nigro, Giampiero (coord.): Francesco di Marco Datini. L'uomo, il mercante. Florencia, Fondazione di Instituti di Storia Economica F. Datini, 2010.

HeERs, Jacques: Occidente durante los siglos XIV y XV. Barcelona, Labor, 1984.

HyDE, John Kenneth. «Real and imaginary journeys in the later middle ages», Bulletin of the John Rylands Library, Vol. 65, (1982/83), pp. I25-I47.

Ellıot, John Huxtable: El Viejo Mundo y el Nuevo (I492-I650). Madrid, Alianza Editorial, I972

IGUAL LuIs, David: «¿Crisis? ¿Qué crisis? El comercio internacional en los reinos hispánicos de la Baja Edad Media», Edad Media, Revista de Historia, no8, (2007), pp. 203-223. p. 209. 
Ladero Quesada, Miguel Ángel: «La Guerra del Estrecho» en Guerra y diplomacia en la Europa Occidental, I280-I480. XXXI Semana de Estudios Medievales, Estella, I9 a 23 de julio 2004, Ladero Quesada, Miguel Ángel (et. alii), Pamplona, Institución Príncipe de Viana, 2005, pp. 255-294.

LANE, Frederic Chapin: Venetian ships and shipsbuilder of the Renaissance. Baltimore, JHUP, I934

Lloyd, Henry: The English wool trade in the Middle Ages. Cambridge, Cambridge University Press, I977.

López de Coca CASTAÑer, José Enrique: «Las galeras venecianas de Poniente y Berbería desde la perspectiva española», Medievalismo: boletín de la Sociedad Española de Estudios Medievales, $\mathrm{n}^{\mathrm{O}} \mathrm{I} 6,(2006)$, pp. I13-172.

Manonni, Tiziano: La rivoluzione mercantile nel Medioevo: uomini, merci e strutture degli scambi nel Mediterraneo. Genova, Il Portolano, 2009.

Melis, Federigo: «La participación toscana en la navegación atlántica» en Las rutas del Atlántico, Trabajos del Noveno Coloquio Internacional de Historia Marítima (Sevilla, 2430 Septiembre 1967) Coloquio Internacional de Historia Marítima, Sevilla, Escuela de Estudios Hispanoamericanos, I969, pp. 28I-293.

Miranda, Flãvio: «Portugal y las redes mercantiles en la Europa atlántica a finales de la Edad Media» en Carvajal de la Vega, David; AÑíbarro Rodríguez, Javier y Vitores CASADO, Imanol (eds.): Redes sociales y económicas en el mundo bajomedieval. Valladolid, Castilla Ediciones, 200I, pp. 155-I76.

Mollat du Jourdin, Michel: Europa y el Mar. Barcelona, Crítica, I993.

MunRo, John: «The Low Countries' export trade in textiles with the Mediterranean basin, I200-I600: a cost-benefit analysis of comparative advantages in overland and maritime trade routes», International journal of maritime history, $\mathrm{n}^{\circ}$ II, (I999), pp. I-30.

MuÑoz Pomer, María Rosa; Navarro Espinach, Germán e Igual Luis, David: «El comercio portugués en el Mediterráneo Occidental durante la Baja Edad Media» en La Península Ibérica entre el Mediterráneo y el Atlántico; siglos XIII-XIV. Cádiz, I-4 de abril de 2003, González Jiménez, Manuel y Romero - Camacho, Isabel (eds.), Cádiz, Diputación de Cádiz, 2006. pp. 73-84. p

North, Douglass Cecil y Thomas, Robert Paul: El nacimiento del mundo occidental, una nueva historia económica (90o-I70o). Madrid, Siglo Veintiuno de España, I978.

OHLER, Norbert: «I mezzi di trasporto terrestre e marittimi» en Gensını, Sergio (dir.): Viaggiare nel Medioevo. Roma, Pacini: Fondazione Centro di Studi sulla Civiltà del Tardo Medioevo San Miniato, 2000.

Ortega Villoslada, Antonio: «Viaje a Flandes e Inglaterra ¿Cabotaje o recta vía?», Espacio, Tiempo y Forma, Serie III, $H^{a}$ Medieval, $\mathrm{n}^{\mathrm{o}} \mathrm{I} 6$, (2003), pp. 229-250.

Ortega Villoslada, Antonio: El reino de Mallorca y el mundo atlántico (I230-I349). Evolución político mercantil. Oleiros, Netbiblo, 2008.

OrTEga VilLOSLADA, Antonio: «Las relaciones marítimo-comerciales entre el Mediterráneo y el Atlántico. El papel de Mallorca en el comercio entre oriente y Occidente. Siglos XIV y XV», Memòries de l'Acadèmia Mallorquina d'Estudis Genealògics, nº 20, (2010), pp. 6I-80.

PARRY, John Horace: El descubrimiento del Mar. Barcelona, Grijalbo, I986.

Penrose, Boies: Travel and Discovery in the Renaissance (I420-I62O). Cambridge, Harvard University Press, 1952.

PHILliPs, John Roland. The medieval expansion of Europe. Oxford, Oxford University Press, I988.

PISTARINO, Geo: «Presenze ed influenze italiane nel sud della Spagna (secc. XII-XV)» en Presencia italiana en Andalucía, siglos XIV-XVII. Actas I coloquio hispano italiano, TorRES 
Ramírez, Bibiano y Hernández Palomo, José (eds.). Sevilla, Escuela de Estudios Hispano Americanos, I985, pp. 2I-5I.

Pounds, Norman: Historia económica de la Europa Medieval. Barcelona, Crítica, 1987.

Reyerson, Kathryn: «Commerce and communications» en Abulafia, David (ed.): The New Cambridge Medieval History. Volume V c. I198- c. I300. Cambridge, Cambridge University Press, 2008, pp. 50-70. pp. 57-60.

Riera Melis, Antoni: «El context mediterrani de la primera fase del regnat de Jaume II (I29I-I3II): conflictivitat i canvis», Anales de la universidad de Alicante. Historia Medieval, $\mathrm{n}^{\mathrm{o}}$ I2, (1999), pp. 183- 205.

Rogers, Francis M.: «The Vivaldi Expedition», Annual Report of the Dante Society, with Accompanying Papers, $\mathrm{n}^{\mathrm{o}}$ 77, (I955), pp. 3I-45.

Sabatino López, Roberto: «Majorcans and Genoese on the North Sea Route in the Thirteenth Century», Revue belge de philologie et d'histoire, $\mathrm{n}^{\circ}$ 29, (4), (I95I), pp. II63-II79.

SABATINo López, Roberto: La revolución comercial en la Edad Media. Barcelona, El Albir, I982.

Scammell, Geoffrey Vaughan: The World Emcompassed: The First Maritime Empires, c. 80oI650, Berkley, University of California Press, I98I.

SoldANI, María Elisa: «Dal Mediterraneo all'Atlantico. Gli uomini d'affari fiorentini nella Penisola Ibrica tra Tre e Quattrocento», en Vespucci, Firenze e le Americhe. Atti del convegno di studi, Firenze, 22-24 novembre 20I2, Pinto, Giuliano; Rombal, Leonardo y Tripodi, Claudio (coords.), Florencia, Leo S. Olschki Editore, 20I4, p. 43- 72.

Solórzano Telechea, Jesús Ángel: «Medieval Seaports of the Atlantic Coast of Spain», International journal of maritime history, Vol. 2I, $\mathrm{n}^{\circ} . \mathrm{I},(2009)$, pp. 8I-IOO. pp. 95-97.

TANGHERONI, Marco: «Rapporti economici tra il Mediterraneo el'Europa settentrionale», Revista d'historia Medieval, no 6, (I995), pp. 53-62.

TANGHeroni, Marco: Commercio e navigazione nel medioevo. Roma, Laterza, I996.

Tuccl, Ugo: «Navi e navigazioni all'epoca delle crociate» en Ortalli, Gherardo (et alii): Genova, Venezia, il levante nei secoli XII-XIV. Venecia, Istituto Veneto di Scienze, Lettere ed Arti, 200I, pp. 273-294.

Verlinden, Charles: «Dal Mediterraneo all'Atlantico» en Devoto, Giacomo: Contributi per la storia económica. Prato, Istituto Internazionale di storia económica F. Datini, I975, pp. 27-5I.

Weckman, Luis: «The middle ages in the discovery of America», Speculum, 26 (I), (I95I), pp. I30-I4I. 
Calidad de Revistas

Científicas Españolas

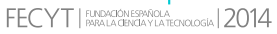

AÑO 2017

ISSN: 0214-9745

E-ISSN 2340-1362

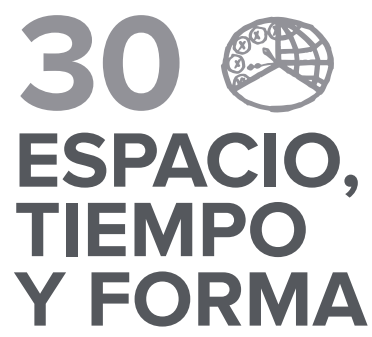

SERIE III HISTORIA MEDIEVAL

REVISTA DE LA FACULTAD DE GEOGRAFİA E HISTORIA

\section{Artículos · Articles}

15 Vicente Ángel Álvarez Palenzuela

Del gobierno de la oligarquía a la tiranía de D. Álvaro (1435-1439). From the Government of the Oligarchy to the Tyranny of Don Álvaro (1435-1439)

83 Carlos Barquero GoÑ

Hospitalarios y obispos en Castilla durante los siglos XII y XIII Hospitallers and Bishops in Castile during the Twelfth and Thirteenth Centuries

Gonzalo Carrasco García

Ritual político, antropología e historiografía bajomedieva hispánica P Political Ritual, Anthropology and Scholarship on Late Medieval Spain

193 Albert Cassanyes Roig

El cabildo catedralicio de Mallorca y la política de Fernando II el Católico. The Cathedral Chapter of Majorca and the Politics of Fernando II the Catholic

\section{ELISA CASELL}

El antijudaísmo en la administración de justicia ordinaria. E caso de un corregidor castellano de finales del siglo XV. Anti-Judaism in the Administration of Justice. The Case of a Castilian Magistrate in the Late Fifteenth Century

\subsection{MÁxIMO DIAGO HERNANDO}

Violencia en las actuaciones políticas del clero catedralicio en Plasencia a fines del siglo XV y comienzos del XVI - Violence in the Politica Action of the Cathedral Clergy of Plasencia in the Latter Fifteenth and Early Sixteenth Centuries

\section{MARISOL ENCINAS MANCHADO}

La inscripción medieval de la estela romana de Dombellas (Soria): su razonable relación con la leyenda de Muño Sancho de Finojosa - The Medieval Inscription on the Roman Stele found in Dombellas (Soria) and its Probable Relation to the Legend of Muño Sancho de Finojosa

309 María jesús Fuente

Más allá del amor: mujeres moras y judías víctimas de violencia en la Castilla del siglo XV . Beyond Love: Muslim and Jewish Women Victims of Violence in Fifteenth-Century Castile
335 María Francisca García Alcázar

Los «continos» reales de Castilla durante la Baja Edad Media. Estado de la cuestión. Royal Continos in Castile during the Late Middle Ages. A State of the Question

359

María Dolores García Oliva

Conflictos en torno a las tierras comunales en el término de Plasencia hacia finales de la Edad Media . Conflicts Concerning the Communal Lands of Plasencia at the End of the Middle Ages

387 SANTIAGO GONZÁlEZ SÁNCHEZ

Las Cortes durante la minoría de Juan II de Castilla . The Cortes during the Minority of Juan II of Castile

\subsection{Francisco Marmolejo Cantos}

Movimientos migratorios en el reino de Granada. El caso de La Torrecilla, despoblado del alfoz de Coín (Málaga) - Migratory Movements in the Kingdom of Granada. The Case of La Torrecilla, a Deserted Settlement in the Hinterland of Coín (Málaga)

4.85 ÁNGEL ROZAS ESPAÑOL una ruta comercial . The Atlantic Route (Thirteenth and Fourteenth Centuries): Analysis of the Development of a Trade Route

505 JuAn José SÁnchez CARRAsco

Las dos dotaciones fundacionales del monasterio de Santa María de la Concepción de Granada . The Two Founding Endowments of the Monastery of Santa María de la Concepción of Granada

539 Josué VILLA PRIETO

Cronística y nobleza en la Italia bajomedieval: la Casa de Este (Ferrara-Módena-Reggio) - Chronicles and Nobility in Italy during the Late Middle Ages: The House of Este (Ferrara-Modena-Reggio)

\section{Evocación · Evocation}

575 FRANCISCO ABAD NEBOt

Joan Reglà (27 de Julio de 1917- 27 de Diciembre de 1973) y el medievalismo · Joan Reglà (27 of July, 1917 - 27 of December, 1973) and Medievalism 


\section{0}

\section{ESPACIO,}

\section{TIEMPO}

Y FORMA

UกED

SERIE III HISTORIA MEDIEVAL

REVISTA DE LA FACULTAD DE GEOGRAFÍA E HISTORIA

\section{Libros · Books}

583 Aguiar Andrade, Amélia, Millán da Costa, Adelaide (eds.), La ville médiévale en débat (ANA María Rivera Medina)

591 CASELLI, Elisa, Antijudaïme, pouvoir politique et administration de la justice. Juifs, chrétiens et converts dans I' espace jurisdictionnel de la Chancillería de Valladolid (XVé-XVle siècles) (ENRIQUE CANTERA MONTENEGRO)

595 GonzÁlez Mínguez, César, A vueltas con la crisis bajomedieval. El entorno Cantera Montenegro) económico del reinado de Fernando IV de Castilla (1295-1312) (ENRIQUE

601 JuncosA BONET, Eduard, Estructura y dinámicas de poder en el señorío de Tarragona. Creación y evolución de un dominio compartido (ca. 1118-1462) (RAFAel NaRbona VizCAínO)

607 Peel, Christine (trad.), Guta Lag. The Law of the Gotlanders (José Miguel García Pimentel

611 Rodríguez WitTMAn, Kevin, Las islas del fin del mundo. Representación de ZALACAIN)

las afortunadas en los mapas del occidente medieval (ROBERTO J. GONZÁLEZ

615 Torres Jiménez, Raquel y Ruiz Gómez, Francisco (eds.), Órdenes militares y construcción de la sociedad occidental (siglos XII-XV) (JOsÉ Manuel Rodríguez García)

619 Zapatero, MARIANA, Alimentación y abastecimiento de carne. El caso castellano durante la Baja Edad Media: mercado, consumo y cultura (ANA María Rivera Medina) 